\title{
Changes in lung volumes and airway responsiveness following haematopoietic stem cell transplantation
}

\author{
G. Barisione*, A. Bacigalupo* , E. Crimi" ${ }^{\mp}$, M.T. Van Lint ${ }^{\#}$, \\ T. Lamparelli ${ }^{\#}$ and V. Brusasco
}

ABSTRACT: Changes in lung volume occur following haematopoietic stem cell transplantation (HSCT); airway hyperresponsiveness was occasionally reported, without mechanistic explanation. The present authors studied 17 patients by standard methacholine (MCh) challenge before and then 3 and 12 months after HSCT ( $n=16$ and $n=13$, respectively). Another 6 patients were challenged before and 3 months after HSCT using a modified challenge to investigate the effect of deep inhalations.

No patient developed bronchiolitis obliterans or bronchiolitis obliterans organising pneumonia. At 3 months, forced vital capacity (FVC) was significantly reduced by $0.33 \pm 0.55 \mathrm{~L}$, forced expiratory volume in one second (FEV1) by $0.31 \pm 0.50 \mathrm{~L}$, total lung capacity (TLC) by $0.39 \pm 0.37 \mathrm{~L}$ and single-breath diffusing capacity of the lung for carbon monoxide (DL,CO) by $15 \pm 12 \%$. At 12 months, TLC decreased by $0.43 \pm 0.36 \mathrm{~L}$ and $D \mathrm{~L}$,Co by $8 \pm 8 \%$. With standard challenge, no significant changes in FEV1 response to $\mathrm{MCh}$ were observed after HSCT but FVC decreased significantly less after HSCT compared with prior to HSCT, suggesting less air trapping. With modified challenge, deep inhalations reversed the $\mathrm{MCh}$-induced decrease in partial expiratory flow more after HSCT compared with before HSCT and this correlated with TLC decrements.

In conclusion, an increase in airway responsiveness is unlikely after haematopoietic stem cell transplantation, at least in patients without pulmonary complications, and mechanisms opposing airway narrowing may blunt the bronchoconstrictor response.

KEYWORDS: Deep inhalations, haematological malignancies, lung restriction, methacholine

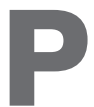
atients undergoing allogeneic haematopoietic stem cell transplantation (HSCT) are susceptible to developing severe pulmonary complications [1, 2], including bronchiolitis obliterans and bronchiolitis obliterans organising pneumonia (BOOP). The former has a reported incidence of $0-48 \%$ and results in a purely obstructive functional abnormality at late onset (around $1 \mathrm{yr}$ post-HSCT), whereas the latter is rare $(<2 \%)$ and characterised by an early (usually within the first 100 days) restrictive abnormality associated with a reduction of single-breath diffusing capacity of the lung for carbon monoxide $(D \mathrm{~L}, \mathrm{CO})[3]$.

Prospective studies of patients undergoing HSCT have shown that lung function changes also occur independently of the development of BOOP or bronchiolitis obliterans [4-6]. Collectively, these studies have shown consistent reductions of forced vital capacity (FVC), forced expiratory volume in one second (FEV1), total lung capacity (TLC) and DL,CO, thus suggesting the development of a restrictive disorder possibly due to the concomitant treatments. An increase in airway responsiveness to methacholine (MCh) was occasionally reported either before $[7,8]$ or after [8] HSCT. The clinical relevance of airway hyperresponsiveness in transplant recipients may vary depending on its underlying mechanism. In lung transplant recipients it occurs frequently [912] and has been regarded as a risk factor for the development of bronchiolitis obliterans [11, 12], possibly reflecting an early derangement of airway mechanics. Alternatively, airway hyperresponsiveness may be the consequence of breathing at low lung volume, thus reflecting a reduced elastic load on a normally behaving airway smooth muscle.

The present prospective study aimed to investigate whether changes in airway responsiveness occur in patients undergoing HSCT. Moreover, as bronchial responsiveness is the result of both

\section{AFFILIATIONS}

*Dept of Preventive and Occupational Medicine - Laboratory of Respiratory Pathophysiology,

\#Dept of Haematology, San Marino University, and

"Unit of Respiratory Pathophysiology, Dept of Internal Medicine, University of Genoa, Genova, Italy.

\section{CORRESPONDENCE}

G. Barisione

U.0. Medicina Preventiva e del Lavoro - Laboratorio di Fisiopatologia Respiratoria

Azienda Ospedaliera Universitaria San Martino

Largo Rosanna Benzi 10

16132 Genova

Italy

Fax: 390105553367

E-mail: giovanni.barisione@

hsanmartino.it

Received:

October 232007

Accepted after revision:

July 242008

STATEMENT OF INTEREST

None declared.

European Respiratory Journal Print ISSN 0903-1936

Online ISSN 1399-3003 
airway smooth muscle contractility and mechanical modulation of airway narrowing $[13,14]$, a standard MCh challenge was first used to assess the airway response by FEV1 and FVC followed by a modified challenge to evaluate the bronchodilator effect of deep inhalations using a parameter of airway calibre not preceded by full lung inflation.

\section{METHODS}

\section{Subjects characteristics}

Between 2004 and 2007, 23 Caucasian patients undergoing allogeneic HSCT (sourcing from bone marrow) for haematological malignancies were studied (table 1). All patients were in stable clinical conditions at the time of study and none had a history of bronchial asthma, chronic obstructive pulmonary disease, and/or other significant respiratory disease. The study protocol was approved by the local Ethics Committee (Genova, Italy) and all patients gave written informed consent.

\section{Clinical data and conditioning regimen}

The patient's underlying disease state included acute myeloid leukaemia, non-Hodgkin's malignant lymphoma and other conditions. All patients received a myeloablative treatment including either total body irradiation (TBI) $\leqslant 12$ Gy or a nonTBI-based regimen. They were prepared with a conventional conditioning regimen including cyclophosphamide, cyclosporine A, methotrexate, and appropriate antibiotic prophylaxis. To prevent graft-versus-host disease (GvHD), cyclosporine A $\left(6-10 \mathrm{mg} \cdot \mathrm{kg}^{-1}\right.$ daily) was continued for $\geqslant 1 \mathrm{yr}$ and 17 patients also received antithymocyte globulin [15]. High-resolution computed tomography (HRCT) of the chest was used to assess for signs of bronchiolitis obliterans and/or BOOP. The diagnosis and staging of acute and chronic GvHD were established using clinical, histological and laboratory criteria [16]. Patients diagnosed with acute GvHD were treated with prednisolone ( $2 \mathrm{mg} \cdot \mathrm{kg}^{-1}$ daily) for five consecutive days.

\begin{tabular}{|c|c|c|}
\hline TABLE 1 & \multicolumn{2}{|c|}{$\begin{array}{l}\text { Main anthropometric and clinical characteristics } \\
\text { of study subjects }\end{array}$} \\
\hline Male/female & & $16 / 7$ \\
\hline Age yrs & & $39 \pm 11$ \\
\hline Height m & & $1.73 \pm 0.09$ \\
\hline $\mathrm{BMI} \mathbf{k g} \cdot \mathrm{m}^{-2}$ & & $25.5 \pm 4.7$ \\
\hline Smoking sta & us current/former/never & $8 / 2 / 13$ \\
\hline \multicolumn{3}{|c|}{ Haematological disease } \\
\hline Acute myel & id leukaemia & 9 \\
\hline Non-Hodgk & 's malignant lymphoma & 5 \\
\hline Other & & 9 \\
\hline \multicolumn{3}{|c|}{ Haematological treatments } \\
\hline TBI during & yeloablative conditioning period yes/no & $12 / 11$ \\
\hline CsA level a & 3 months post-HSCT $\mathrm{ng} \cdot \mathrm{mL}^{-1}$ & $152 \pm 128$ \\
\hline HRCT signs & f BO or BOOP & 0 \\
\hline GvHD acute & hronic & $4 / 6$ \\
\hline \multicolumn{3}{|c|}{$\begin{array}{l}\text { Data are presented as absolute numbers or mean } \pm \text { SD. BMI: body mass index; } \\
\text { TBI: total body irradiation ( } \leqslant 12 \text { Gy); CsA: cyclosporine A; HSCT: haemato- } \\
\text { poietic stem cell transplantation; HRCT: high-resolution computed tomography; } \\
\text { BO: bronchiolitis obliterans; BOOP: bronchiolitis obliterans organising pneu- } \\
\text { monia; GVHD: graft-versus-host disease. }\end{array}$} \\
\hline
\end{tabular}

\section{Lung function measurements}

Standard spirometry and flow-volume curves (FEV1 and FVC) were obtained using a mass flowmeter (VIASYS-SensorMedics Inc., Yorba Linda, CA, USA) and numerical integration of the flow signal, according to the American Thoracic Society (ATS)/ European Respiratory Society (ERS) recommendations [17]. Airway resistance (Raw) was measured by whole body plethysmograph (V62J; VIASYS-SensorMedics Inc.), while the subject was panting at a frequency slightly $>1.5 \mathrm{~Hz}$. Immediately after each Raw measurement, thoracic gas volume (TGV) was obtained by panting against a closed shutter at a frequency ranging from 0.5 to slightly $<1.0 \mathrm{~Hz}$, and specific airway conductance was calculated as $1 /(\mathrm{TGV} \cdot$ Raw). Functional residual capacity (FRC) was corrected for the difference between TGV and the endexpiratory volume of the four to six preceding tidal breaths. After the opening of the shutter, the subject resumed tidal breaths and at the end of one tidal breath performed a maximum slow expiration followed closely by a maximum inspiration allowing measurement of TLC and residual volume (RV). TLC was obtained by adding the inspiratory vital capacity to RV. The measurements were performed according to the ATS/ERS recommendations [18]. The DL,CO was measured (Vmax22D; VIASYS-SensorMedics Inc.) and the predicted values were adjusted for the effective blood haemoglobin concentration $\left(\mathrm{g} \cdot \mathrm{dL}^{-1}\right)$ obtained closest to the time the measurement of $\mathrm{DL}, \mathrm{CO}$ was performed [19]. Quality control of lung function measurements was regularly made according to the ATS/ERS recommendations [17-19]. All predicted values for spirometry, lung volumes and DL,CO were obtained from QUANJER et al. [20] for the Caucasian European population.

Partial flow-volume curves were obtained and superimposed at constant absolute lung volume by measuring TGV and then asking the subject to expire forcefully from end-tidal inspiration to RV immediately after the reopening of the shutter. In each subject, partial forced expiratory flow ( $V^{\prime}$ part) was always measured at the same absolute lung volume of $30-40 \%$ of the pre-HSCT baseline FVC, depending on the largest change in RV after MCh inhalation [21].

\section{Aerosol generation and delivery}

Airway responsiveness was tested by $\mathrm{MCh}$ challenge using a dosimeter method. Solutions of $\mathrm{MCh}$ of 0.2 and $1 \%$ were prepared by adding $3 \mathrm{~mL}$ of distilled water to dry powder MCh chloride (Laboratorio Farmaceutico Lofarma, Milano, Italy). Aerosols were generated and delivered via a DeVilbiss 646 nebuliser (DeVilbiss Health Care Inc., Somerset, PA, USA) attached to a KoKo (Rosenthal-French) breath-activated dosimeter (Ferraris, Louisville, CO, USA), driven by compressed air $\left(30 \mathrm{lb} \cdot \mathrm{in}^{-2}\right)$ with $1-\mathrm{s}$ actuations. Aerosol output at the mouth was $10 \mu \mathrm{L}$ per actuation. Aerosols were inhaled during quiet tidal breathing in a sitting position.

\section{Experimental procedures}

All pulmonary function tests (PFTs) and bronchial challenges pre-HSCT were obtained before each conditioning regimen was started and out of acute GvHD episodes.

Standard MCh challenge study

Approximately 1 week before, and 3-12 months after HSCT, 17 patients were challenged with a standard incremental $\mathrm{MCh}$ 
protocol. After 20 tidal inhalations of saline as a control, subjects inhaled increasing doses of MCh until a decrease of $\mathrm{FEV} 1 \geqslant 20 \%$ of control was achieved. Increasing MCh doses from 20, 40, 80, 160, 300, 600, 1,200 and 2,400 $\mu \mathrm{g}$ were obtained by using two $\mathrm{MCh}$ concentrations $\left(2.0 \mathrm{mg} \cdot \mathrm{mL}^{-1}\right.$ and $10 \mathrm{mg} \cdot \mathrm{mL}^{-1}$ ) with appropriate numbers of tidal breaths (one to 24). The delay time between serial inhalations (i.e. from the start of one dose to the start of the next) ranged between 30 and 60 s. FVC and FEV1 were measured once at each step and the dose of MCh causing a reduction of FEV1 by $20 \%$ (provocative concentration causing a $20 \%$ fall in FEV1 (PD20)) was determined by interpolating between two adjacent points of log dose-response curve. To overcome the difficulty arising when a subject's FEV1 failed to drop by $20 \%$, the slope of the relationship of percentage reduction in FEV1 on the incremental log-transformed doses of the MCh was used as an index of response [22]. The occurrence of air trapping was inferred by submitting the absolute values (L) of both FVC and FEV1 measured at all steps of MCh challenge to a simple linear regression analysis (least square best fitting). In this approach, any decrease in slope or increase in $y$-intercept of FVC versus FEV1 represents an attenuation of air trapping (absolute increase in RV) for a given degree of induced bronchoconstriction (absolute decrease in FEV1) and vice versa [23, 24].

\section{Modified MCh challenge study}

Approximately 1 week before and 3 months after HSCT, six patients who did not participate in the standard study were challenged with three increasing MCh doses (600, 1,200 and $2,400 \mu \mathrm{g}$ ) inhaled during quiet tidal breathing (fig. 1). After each dose, each patient was asked for the occurrence of respiratory discomfort before administering the next dose. After baseline measurements of FVC and FEV1, patients were asked to refrain from taking deep breaths or sighs for $10 \mathrm{~min}$ before the first measurement of $V^{\prime}$ part through to the end of the challenge. All measurements of $V^{\prime}$ part were then taken once $1 \mathrm{~min}$ after the final $\mathrm{MCh}$ dose. Following the last dose $(2,400 \mu \mathrm{g})$ of $\mathrm{MCh}$ and $V^{\prime}$ part measurement, subjects were asked to take five deep inhalations from FRC to TLC during a 30-s period with measurements of $V^{\prime}$ part taken again $1 \mathrm{~min}$ later. The effects of both MCh and deep inhalations on airway calibre were inferred from changes in $V^{\prime}$ part and quantified using a relaxation index (RI).

$$
\mathrm{RI}=\left(\left(V^{\prime} \text { part }_{\mathrm{DIs}}-V^{\prime} \text { part }_{\mathrm{MCh}}\right) / V^{\prime} \text { part }_{\mathrm{Bas}}\right)
$$

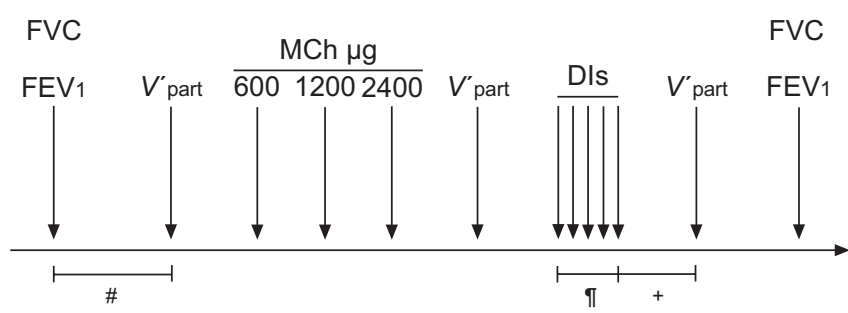

FIGURE 1. Design of modified methacholine (MCh) challenge study. FVC: forced vital capacity; FEV1: forced expiratory volume in one second; $V^{\prime}$ part: partial forced expiratory flow; Dls: deep inhalations. ${ }^{\#:}$ 10-min deep breath prohibition; ?: $30 \mathrm{~s} ;{ }^{+}: 1 \mathrm{~min}$
Where $V^{\prime}$ part DIs, $^{\prime} V_{\text {part }}{ }_{\mathrm{MCh}}$ and $V^{\prime}$ part ${ }_{\text {Bas }}$ are the forced expiratory partial flows measured at the end of MCh challenge following DIs, at the end of $\mathrm{MCh}$ challenge, and at baseline, respectively.

\section{Statistical analysis}

Differences between groups were assessed for significance by an unpaired t-test. Changes within groups were tested by oneor two-factor repeated measures ANOVA with Duncan's posthoc comparisons and Pearson's correlation coefficient. PD20 values were log-transformed before analysis. When an FEV1 fall of $<20 \%$ was recorded after the last 2,400 $\mu \mathrm{g}$ MCh dose, this value was retained as the PD20. Values of $p<0.05$ were considered statistically significant. Data are presented as means \pm SD.

\section{RESULTS}

None of the patients participating in the present study showed radiological signs of bronchiolitis obliterans and/or BOOP on chest HRCT. At 3 months, nine patients showed the presence of transient mono-segmental consolidation, suggestive of Aspergillus infection. In addition, 10 patients showed the presence of acute $(n=4)$ or chronic $(n=6)$ GvHD, especially skin changes and sicca syndrome, with eyes and mouth dryness. At baseline, PFTs were within the predicted normal range (tables 2 and 3), without differences between studies ( $p>0.10$ for all comparisons). When the patients of both groups were considered together, there was a tendency $(p=0.073)$ for TLC to decrease more at 3 months in those receiving than in those not receiving the TBI-based conditioning regimen $(10 \pm 8$ and $5 \pm 6 \%$, respectively).

\section{Standard MCh challenge study}

In the group of patients studied by standard MCh challenge, there was a mild yet statistically significant absolute decrement of FVC $(0.33 \pm 0.55 \mathrm{~L} ; \mathrm{p}=0.030)$, FEV1 $(0.31 \pm 0.50 \mathrm{~L} ; \mathrm{p}=0.026)$ and TLC $(0.39 \pm 0.37 \mathrm{~L} ; \mathrm{p}=0.0007)$ from baseline to 3 months. The latter also showed a reduction of similar magnitude $(0.43 \pm 0.36 \mathrm{~L} ; \mathrm{p}=0.007)$ at 12 months post-HSCT. A significant reduction of $D \mathrm{~L}, \mathrm{CO}$ was observed at 3 and 12 months postHSCT $(15 \pm 12 \% ; p=0.0002$ and $8 \pm 8 \% ; p=0.048$, respectively).

Before HSCT, five patients showed a cumulative PD20 $<800 \mu \mathrm{g}$ $(148-720 \mu \mathrm{g})$ indicating mild-to-borderline airway hyperresponsiveness to $\mathrm{MCh}$, three subjects responded to doses of $800-2,400 \mu \mathrm{g}$, and nine subjects did not respond to $2,400 \mu \mathrm{g}$. Mean PD20 tended to increase from baseline to 12 months $(p=0.064)$, and in five subjects PD20 increased by more than one doubling dose. Moreover, mean slopes of FEV1 versus MCh log-dose at 3 or 12 months were not significantly different from before HSCT $(\mathrm{p}=0.33$ and $\mathrm{p}=0.21$, respectively). Nevertheless, the decrease of FVC for any given reduction of FEV1 was less after HSCT, as pointed out by the significantly lower slopes of absolute values (L) of FVC versus FEV1 $(p=0.010$ and $p=0.008$ at 3 and 12 months, respectively) and a higher $y$-intercept at 12 months $(p=0.014$; fig. 2$)$. These results are suggestive of less air trapping for a given degree of MCh-induced bronchoconstriction.

\section{Modified MCh challenge study}

At 3 months after HSCT, the decrease of TLC was quantitatively but not significantly greater than that observed in 


\begin{tabular}{|c|c|c|c|}
\hline TABLE 2 & $\begin{array}{l}\text { lung funct } \\
\text { holine (MCr }\end{array}$ & $\begin{array}{l}\text { data of st } \\
\text { hallenge st }\end{array}$ & $\begin{array}{l}\text { lard } \\
y\end{array}$ \\
\hline \multirow[t]{2}{*}{ Parameters } & \multirow[t]{2}{*}{ Pre-HSCT ${ }^{\#}$} & \multicolumn{2}{|c|}{ Post-HSCT } \\
\hline & & 3 months & 12 months $^{+}$ \\
\hline FVC L & $4.78 \pm 0.99$ & $4.45 \pm 0.84^{\S}$ & $4.55 \pm 1.21$ \\
\hline$\%$ pred & $113 \pm 15$ & $108 \pm 16$ & $107 \pm 14$ \\
\hline FEV 1 L & $3.96 \pm 0.80$ & $3.65 \pm 0.75^{f}$ & $3.72 \pm 0.96$ \\
\hline$\%$ pred & $111 \pm 16$ & $106 \pm 15$ & $104 \pm 14$ \\
\hline FEV $1 /$ FVC & $0.81 \pm 0.08$ & $0.81 \pm 0.07$ & $0.82 \pm 0.08$ \\
\hline TLC L & $6.44 \pm 1.10$ & $6.04 \pm 1.0^{\# \#}$ & $5.99 \pm 1.36^{\bullet \bullet}$ \\
\hline$\%$ pred & $104 \pm 9$ & $100 \pm 11$ & $98 \pm 11$ \\
\hline FRC L & $2.93 \pm 0.45$ & $3.02 \pm 0.57$ & $3.01 \pm 0.83$ \\
\hline$\%$ pred & $94 \pm 6$ & $97 \pm 11$ & $97 \pm 20$ \\
\hline RV L & $1.56 \pm 0.39$ & $1.55 \pm 0.35$ & $1.42 \pm 0.48$ \\
\hline$\%$ pred & $90 \pm 19$ & $87 \pm 16$ & $82 \pm 22$ \\
\hline $\mathrm{sGaw} \mathrm{L} \cdot \mathrm{s}^{-1} \cdot \mathrm{cmH}_{2} \mathrm{O}^{-1}$ & $0.21 \pm 0.04$ & $0.21 \pm 0.03$ & $0.23 \pm 0.04$ \\
\hline$\%$ pred & $92 \pm 14$ & $91 \pm 10$ & $95 \pm 16$ \\
\hline $\begin{array}{l}\text { DL,Co mL. } \min ^{-1} . \\
\mathrm{mmHg}^{-1}\end{array}$ & $26.1 \pm 6.21$ & $19.7 \pm 4.89$ & $23.2 \pm 6.10$ \\
\hline$\%$ pred for $\mathrm{Hb}$ & $90 \pm 14$ & $75 \pm 14^{++}$ & $80 \pm 16^{\S \S}$ \\
\hline \multicolumn{4}{|l|}{ MCh FEV 1} \\
\hline PD20 log $\mu \mathrm{g}$ & $3.09 \pm 0.39$ & $3.19 \pm 0.37$ & $3.23 \pm 0.24$ \\
\hline Slope units & $-0.17 \pm 0.10$ & $-0.15 \pm 0.10$ & $-0.15 \pm 0.11$ \\
\hline
\end{tabular}

Values are expressed as mean \pm SD. HSCT: haematopoietic stem cell transplantation; FVC: forced vital capacity; \% pred: \% predicted; FEV1: forced expiratory volume in one second; TLC: total lung capacity; FRC: functional residual capacity; RV: residual volume; sGaw: specific airway conductance $\mathrm{D} \mathrm{L}, \mathrm{CO}$ : diffusing capacity of the lung for carbon monoxide; $\mathrm{Hb}$ : haemoglobin; PD20: provocative dose (log-transformed) of MCh causing a $20 \%$ fall in $\mathrm{FEV}$.

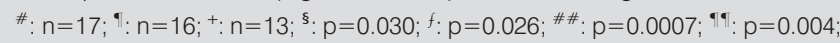
${ }^{++}: p=0.0002 ;$ \$ $: p=0.048$ (all versus baseline). $1 \mathrm{~L} \cdot \mathrm{s}^{-1} \cdot \mathrm{cmH}_{2} \mathrm{O}^{-1}$ $=10.2 \mathrm{~L} \cdot \mathrm{s}^{-1} \cdot \mathrm{kPa}^{-1} ; 1 \mathrm{~mL} \cdot \mathrm{min}^{-1} \cdot \mathrm{mmHg}^{-1}=0.335 \mathrm{mmol} \cdot \mathrm{min}^{-1} \cdot \mathrm{kPa}^{-1}$.

patients participating in the standard challenge study $(0.85 \pm 0.57 \mathrm{~L}$ versus $0.39 \pm 0.37 \mathrm{~L}$, respectively; $\mathrm{p}=0.23)$, although it failed to achieve the pre-set level of statistical significance with respect to pre-HSCT values $(\mathrm{p}=0.053)$. DL,CO was reduced by an extent that was similar to that observed in the standard MCh challenge study $(20 \pm 13 \%$; $p=0.016$ versus pre-HSCT).

The decrease of $V^{\prime}$ part induced by the cumulative MCh dose of $4,200 \mu \mathrm{g}$ was similar before and after HSCT $(\mathrm{p}=0.95)$. Repeated deep inhalations taken after $\mathrm{MCh}$ reversed the reduction of $V^{\prime}$ part significantly after $(\mathrm{p}=0.020)$ but not before HSCT $(\mathrm{p}=0.79)$; this difference in the effect of deep inhalations was statistically significant ( $p=0.043$ for the interaction term; fig. 3). The relaxant effect of deep inhalations after HSCT was significantly correlated $(\mathrm{r}=0.88 ; \mathrm{p}=0.021)$ with the per cent reduction of TLC (fig. 4).

\section{DISCUSSION}

The main findings of the present study are that: 1) TLC and DL,CO decreased after HSCT, confirming previous studies; 2) airway responsiveness to $\mathrm{MCh}$ as assessed by standard challenge did not change; and 3) the ability of deep inhalations

\begin{tabular}{|c|c|c|}
\hline \multirow{2}{*}{ TABLE 3} & \multicolumn{2}{|c|}{$\begin{array}{l}\text { Baseline lung function data of modified } \\
\text { methacholine challenge study }\end{array}$} \\
\hline & Pre-HSCT ${ }^{\#}$ & 3 months post-HSCT \\
\hline FVC L & $5.26 \pm 0.94$ & $4.71 \pm 1.04$ \\
\hline$\%$ pred & $109 \pm 5$ & $98 \pm 17$ \\
\hline FEV1 L & $4.14 \pm 0.79$ & $3.67 \pm 0.76$ \\
\hline$\%$ pred & $104 \pm 10$ & $93 \pm 17$ \\
\hline FEV $1 /$ FVC & $0.79 \pm 0.04$ & $0.78 \pm 0.05$ \\
\hline TLC L & $7.00 \pm 1.14$ & $6.36 \pm 1.37^{+}$ \\
\hline$\%$ pred & $99 \pm 5$ & $89 \pm 11$ \\
\hline FRC L & $3.25 \pm 0.57$ & $3.25 \pm 0.79$ \\
\hline$\%$ pred & $95 \pm 14$ & $97 \pm 21$ \\
\hline RV L & $1.74 \pm 0.40$ & $1.65 \pm 0.41$ \\
\hline$\%$ pred & $87 \pm 9$ & $83 \pm 18$ \\
\hline $\mathrm{sGaw} \mathrm{L} \cdot \mathrm{s}^{-1} \cdot \mathrm{cmH}_{2} \mathrm{O}^{-1}$ & $0.22 \pm 0.02$ & $0.21 \pm 0.04$ \\
\hline$\%$ pred & $94 \pm 13$ & $90 \pm 16$ \\
\hline$D \mathrm{~L}, \mathrm{CO} \mathrm{mL} \cdot \mathrm{min}^{-1} \cdot \mathrm{mmHg}^{-1}$ & $24.7 \pm 5.11$ & $19.0 \pm 4.36$ \\
\hline \% pred for $\mathrm{Hb}$ & $82 \pm 14$ & $68 \pm 19^{5}$ \\
\hline \multicolumn{3}{|c|}{ 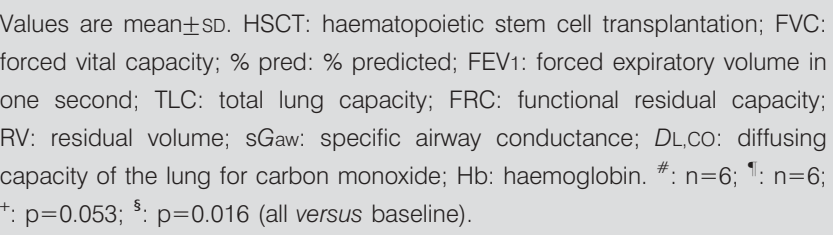 } \\
\hline
\end{tabular}

to reverse induced bronchoconstriction was enhanced after HSCT and this correlated with the reduction in TLC.

Previous studies have documented the occurrence of mild lung restriction $[4,8]$ and reduction of $D \mathrm{~L}, \mathrm{CO}[4-6,8]$ developing within 3-6 months after HSCT, even in the absence of BOOP. In line with previous studies, a mild reduction of TLC and DL,CO was found at 3 months after HSCT without HRCT signs suggestive of BOOP, such as patchy consolidation, groundglass attenuation and/or nodular opacities.

Airway hyperresponsiveness was previously investigated in two studies. Before HSCT, airway hyperresponsiveness to MCh was reported in five out of 25 patients by RoDRIGUEZROISIN et al. [8] and 11 out of 53 patients by KROWKA et al. [7]. In the present study, five out of 23 patients showed mild-toborderline airway hyperresponsiveness. All these figures are within the range of reported prevalence of airway hyperresponsiveness in the general population [25]. Therefore, it cannot be concluded that airway hyperresponsiveness is a feature of haematological malignancies requiring HSCT. In the study by RODRIGUEZ-ROISIN et al. [8], five patients developed airway hyperresponsiveness after HSCT. This finding is not confirmed by the results of the present study. The current authors recognise that the sample size of the present study is rather small, which could have resulted in a type II statistical error (acceptance of a false "null hypothesis"). However, as PD20 tended to increase after HSCT while changes in FEV1 versus MCh log-dose were far from the level of statistical significance, it is unlikely that inclusion of additional patients would have yielded results similar to those of RODRIGUEZRoIsIN et al. [8]. 

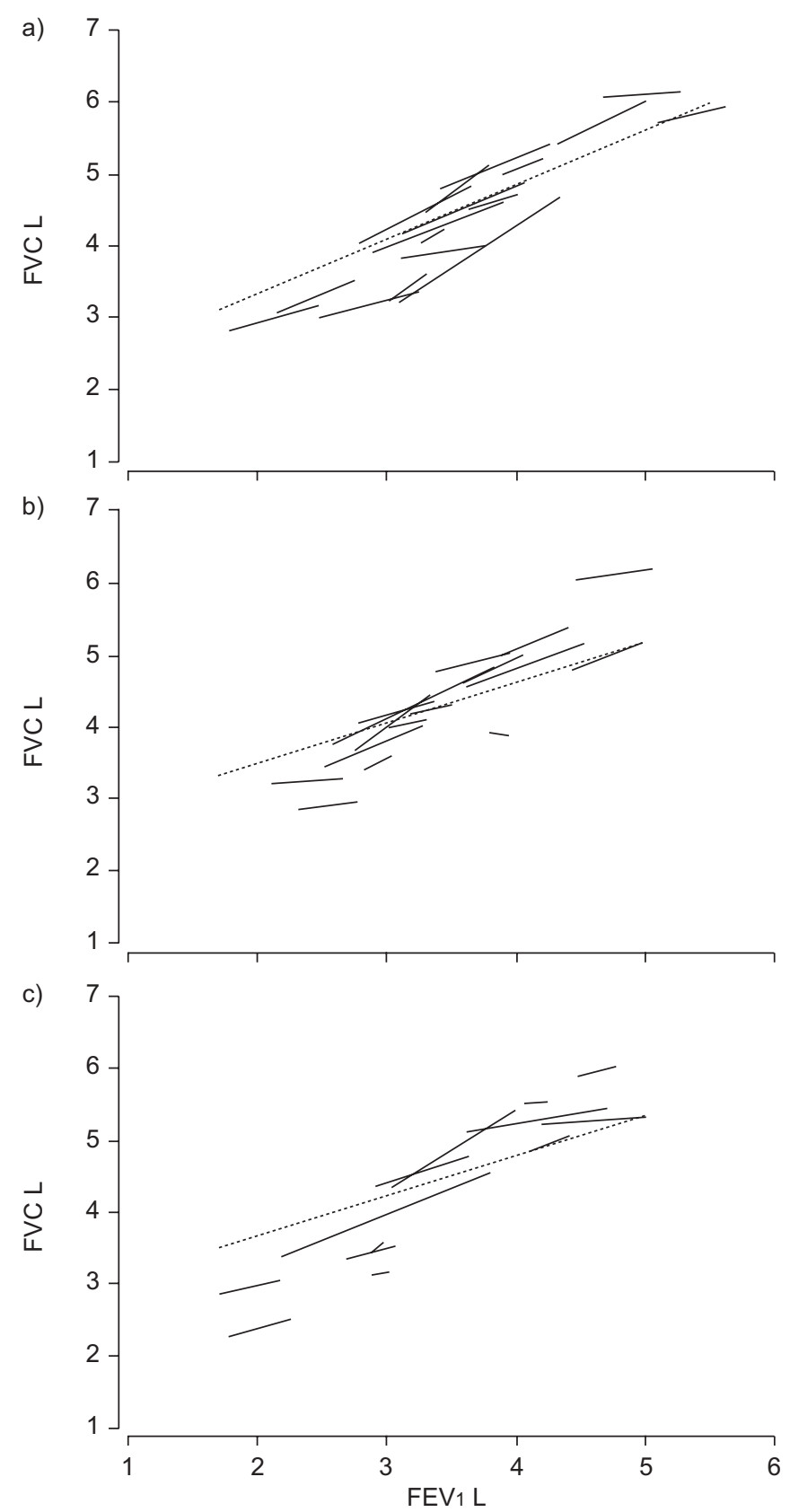

FIGURE 2. Individual $(-)$ and mean $(\cdots \cdots)$ regression lines of absolute values (L) of forced vital capacity (FVC) versus forced expiratory volume in one second (FEV1) during standard methacholine challenge a) before and b) after 3 and c) 12 months from haematopoietic stem cell transplantation (HSCT). The following equations show the mean slopes and $y$-intercepts \pm SD. For the regression line, the right and left ends correspond to the FEV 1 and FVC values at baseline and at maximum response, respectively. a) $y=(0.76 \pm 0.34) x+1.81 \pm 1.38 ; n=17$. b) $y=(0.56 \pm 0.36) x+2.38 \pm 1.26 ; n=16 ; p=0.010$ for the $y$-intercept versus preHSCT values. c) $y=(0.56 \pm 0.35) x+2.54 \pm 1.37 ; n=13 ; p=0.008$ for the slope and $p=0.014$ for the $y$-intercept both versus pre-HSCT.

Apart from the different challenge protocols, other factors may explain the discrepancies between the current and the previous study [8]. Approximately three quarters of the present patients received antithymocyte globulin for GvHD prophylaxis and a

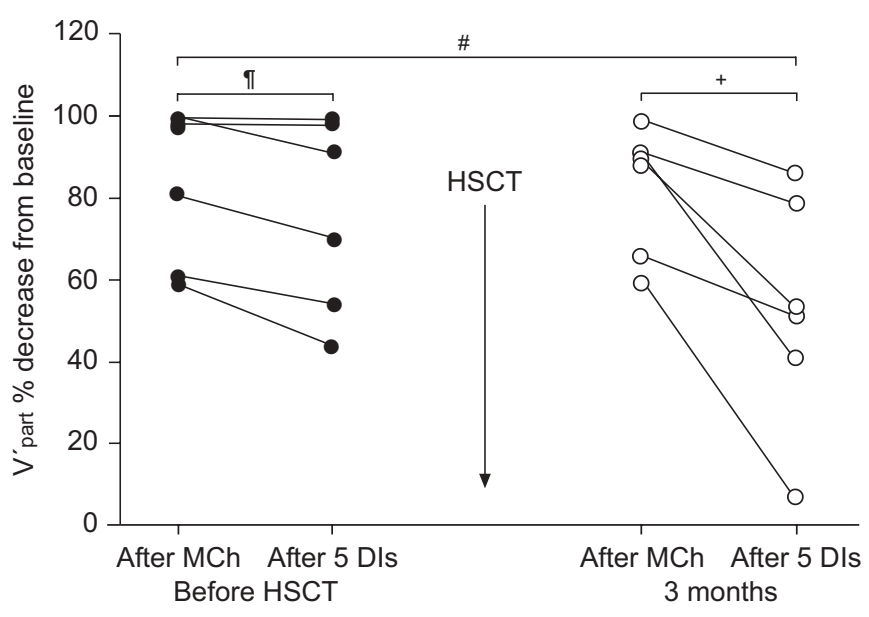

FIGURE 3. Relaxant effect of deep inhalations (DIs) during modified methacholine (MCh) challenge study before and 3 months after haematopoietic stem cell transplantation (HSCT). Per cent decrease of partial forced expiratory flow ( $V^{\prime}$ part) from baseline after both MCh $(4,200 \mu \mathrm{g}$, cumulative) and MCh plus 5 Dls. \#: $p=0.043 ;{ }^{\bullet}: p=0.79 ;{ }^{+}: p=0.020$.

myeloablative conditioning regimen consisting of cyclophosphamide was used and followed by cyclosporine A/methotrexate after HSCT in all patients, whereas in the previous study [8] only two patients received cyclosporine A after HSCT. Moreover, TBI was included in the myeloablative conditioning regimen in about half of the present patients but in the vast majority of those in the study by RODRIGUEZ-ROISIN et al. [8]. Whether these different treatments may have affected airway hyperresponsiveness is a matter of speculation. The effects of cyclosporine A on airway smooth muscle are controversial. In animal models of asthma, cyclosporine A ablated hyperresponsiveness [26], but did not affect the contraction of isolated nonsensitised rat bronchial smooth muscle [27]. In vascular smooth muscle cells, cyclosporine A decreases proliferation and increases apoptosis [28]. Whether

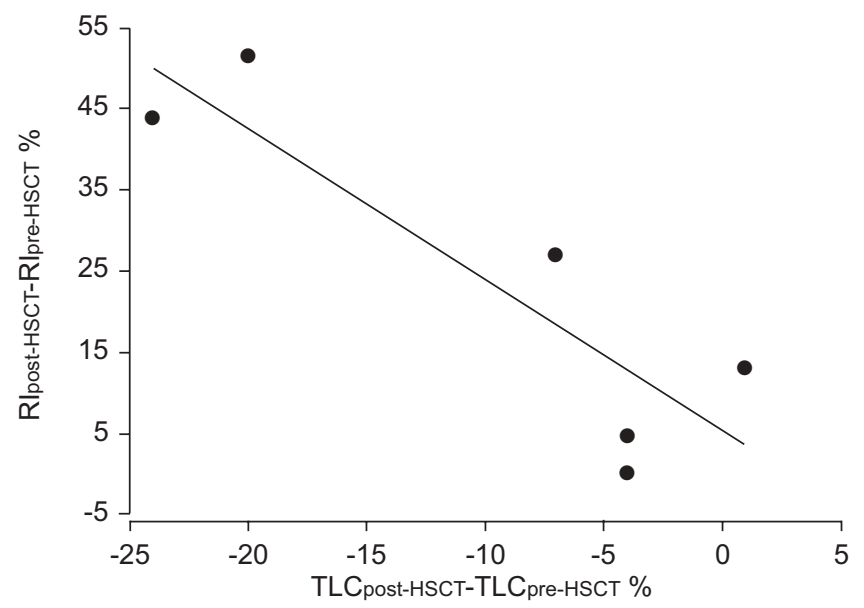

FIGURE 4. Relationship between per cent decrease of total lung capacity (TLC) and increase in relaxant effect of deep inhalations during modified methacholine challenge after haematopoietic stem cell transplantation (HSCT). RI: relaxation index. $r=0.88 ; p=0.021$. 
similar effects may occur in humans is unknown. An increase of airway responsiveness after irradiation was reported in isolated perfused rat lungs [29], but no data in vivo are available. In the present study, no difference between before and after HSCT was observed in the response to MCh when deep inhalations were avoided (modified $\mathrm{MCh}$ challenge study) suggesting that the contractile response of airway smooth muscle was unmodified. Collectively, these data make it unlikely that the different changes in airway responsiveness between the current and the previous study [8] are due to different treatment regimens. Other reasons for increased airway responsiveness in transplanted patients are postHSCT infectious and noninfectious lung complications. In the study by RoDriguez-Roisin et al. [8], six patients had pneumonia of different aetiology and 20 out of 25 acute and/ or chronic GvHD.

Recent studies have shown that airway responsiveness is modulated by the mechanical interdependence between airways and lung parenchyma $[30,31]$. The present authors have found that, for any given decrease of FEV1, the FVC decreased less after HSCT compared with before HSCT, suggesting that, for a given level of airway smooth muscle activation, less air trapping occurred [23, 24]. A similar finding was observed in asthmatic patients with low-dose inhaled corticosteroids, which was attributed to a decrease in the thickness of peripheral airway walls [24]. Moreover, reduced air trapping may reflect a greater stability of peripheral airways, possibly due to an increased load on their walls. The results of the current modified MCh challenge showing a greater bronchodilator effect of deep inhalations, as assessed by $V^{\prime}$ part, tend to support the latter mechanism.

The bronchodilator effect of deep inhalations is proportional to the magnitude of airway distension (strain) [32] and, in turn, to the magnitude of change in lung volume [33]. In the present study, the increased ability of deep inhalations to reverse bronchoconstriction was correlated with the magnitude of the decrease in TLC, suggesting that stress on airway walls was increased despite a reduced lung volume expansion. Although it must be kept in mind that a significant correlation does not prove a definite causality, this finding and the reduced air trapping might suggest that sub-clinical interstitial fibrosis with increased lung elastic recoil may have occurred in these patients thus opposing airway narrowing.

Previous studies have documented the occurrence of airway hyperresponsiveness after lung or heart-lung transplantation [9-12]. Possible explanations for post-transplant airway hyperresponsiveness included denervation hypersensitivity, epithelial damage or changes in mucus properties and clearance, decreased baseline airway calibre, disruption of lymphatic channels or lung perfusion and effects of drugs [9, 10]. In this context, the lack of increase in airway responsiveness after HSCT would suggest that transplantation by itself and the associated treatments are not a cause of airway hyperresponsiveness, whereas organ-specific mechanisms may play a major role in lung transplantation.

In conclusion, the results of the present study suggest that an increase of airway responsiveness is unlikely to occur after haematopoietic stem cell transplantation, at least in patients without pulmonary complications, and mechanisms opposing airway narrowing may blunt the response to constrictor agents.

\section{ACKNOWLEDGEMENTS}

The current authors would like to thank R. Pellegrino (Unit of Respiratory Pathophysiology and Dyspnoea Investigation, S. Croce e Carle Hospital, Cuneo, Italy) for useful criticisms and suggestions. The technical assistance of M. Giuseppina Marras (Dept of Preventative and Occupational Medicine - Laboratory of Respiratory Pathophysiology, San Martino University Hospital, San Martino, Italy) is also gratefully acknowledged.

\section{REFERENCES}

1 Kotloff RM, Ahya VN, Crawford SW. Pulmonary complications of solid organ and haematopoietic stem cell transplantation. Am J Respir Crit Care Med 2004; 170: 22-48.

2 Parimon T, Madtes DK, Au DH, Clark JG, Chien JW. Pretransplant lung function, respiratory failure, and mortality after stem cell transplantation. Am J Respir Crit Care Med 2005; 172: 384-390.

3 Soubani AO, Uberti JP. Bronchiolitis obliterans following haematopoietic stem cell transplantation. Eur Respir J 2007; 29: 1007-1019.

4 Gore EM, Lawton CA, Ash RC, Lipchik RJ. Pulmonary function changes in long-term survivors of bone marrow transplantation. Int J Radiation Oncology Biol Phys 1996; 36: 67-75.

5 Fanfulla F, Locatelli F, Zoia MC, et al. Pulmonary complications and respiratory function changes after bone marrow transplantation in children. Eur Respir J 1997; 10: 2301-2306.

6 Cerveri I, Fulgoni P, Giorgiani G, et al. Lung function abnormalities after bone marrow transplantation in children. Chest 2001; 120: 1900-1906.

7 Krowka MJ, Staats BA, Hoagland HC. A prospective study of airway reactivity before bone marrow transplantation. Mayo Clinic Proc 1990; 65: 5-12.

8 Rodriguez-Roisin R, Roca J, Grañena A, Agustí AGN, Marin P, Rozman C. Lung function in allogeneic bone marrow transplantation recipients. Eur Respir J 1989; 2: 359-365.

9 Glanville AR, Burke CM, Theodore J, et al. Bronchial hyperresponsiveness after human cardiopulmonary transplantation. Clin Sci 1987; 73: 299-303.

10 Maurer JR, McLean PA, Cooper JD, et al. Airway hyperreactivity in patients undergoing lung and heart/ lung transplantation. Am Rev Respir Dis 1989; 139: 1038-1041.

11 Stanbrook MB, Kesten S. Bronchial hyperreactivity after lung transplantation predicts early bronchiolitis obliterans. Am J Respir Crit Care Med 1999; 160: 2034-2039.

12 Reid DW, Walters EH, Johns DP, et al. Bronchial hyperresponsiveness and the bronchiolitis obliterans syndrome after lung transplantation. J Heart Lung Transplant 2005; 24: 489-492.

13 Skloot G, Permutt S, Togias A. Airway hyperresponsiveness in asthma: a problem of limited smooth muscle relaxation with inspiration. J Clin Invest 1995; 96: 2393-2403. 
14 Brusasco V, Crimi E, Barisione G, Spanevello A, Rodarte JR, Pellegrino R. Airway responsiveness to methacholine: effects of deep inhalations and airway inflammation. J Appl Physiol 1999; 87: 567-573.

15 Bacigalupo A, Lamparelli T, Bruzzi P, et al. Antithymocyte globulin for graft-versus-host disease prophylaxis in transplants from unrelated donors: 2 randomised studies from Gruppo Italiano Trapianti Midollo Osseo (GIMTO). Blood 2001; 98: 2942-2947.

16 Koc S, Leisenring W, Flowers MED, et al. Therapy for chronic graft-versus-host disease: a randomised trial comparing cyclosporine plus prednisone versus prednisone alone. Blood 2002; 100: 48-51.

17 Miller MR, Hankinson J, Brusasco V, et al. Standardisation of spirometry. Eur Respir J 2005; 26: 319-338.

18 Wanger J, Clausen JL, Coates A, et al. Standardisation of the measurement of lung volumes. Eur Respir J 2005; 26: 511-522.

19 MacIntyre N, Crapo RO, Viegi G, et al. Standardisation of the single-breath determination of carbon monoxide uptake in the lung. Eur Respir J 2005; 26: 720-735.

20 Quanjer PhH., Tammeling GJ., Cotes JE., Pedersen OF., Peslin R., Yernault JC., Standardised lung function testing. Eur Respir J 1993; 6: 1-99.

21 Crimi E, Pellegrino R, Milanese M, Brusasco V. Deep breaths, methacholine, and airway narrowing in healthy and mild asthmatic subjects. J Appl Physiol 2002; 93: 13841390.

22 O'Connor G, Sparrow D, Taylor D, et al. Analysis of dose response curves to methacholine. Am Rev Respir Dis 1987; 136: 1412-1417.

23 Gibbons WJ, Sharma A, Lougheed D, Macklem PT. Detection of excessive bronchoconstriction in asthma. Am J Respir Crit Care Med 1996; 153: 582-589.

24 Corsico A, Pellegrino R, Zoia MC, Barbano L, Brusasco V, Cerveri I. Effects of inhaled steroids on methacholine-induced bronchoconstriction and gas trapping in mild asthma. Eur Respir J 2000; 15: 687-692.

25 Jansen DF, Timens W, Kraan J, Rijcken B, Postma DS. (A)Symptomatic bronchial hyper-responsiveness and asthma. Respir Med 1997; 91: 121-134.

26 Diasio RB, LoBuglio AF. Immunomodulators: immunosuppressive agents and immunostimulants. In: Hardman JG, Limbird LE, eds. Goodman \& Gilman's: The Pharmacological Basis of Therapeutics. 9th Edn. New York, McGraw-Hill, 1996; pp. 1297-1299.

27 Tavakoli R, Daly RC, McGregor CG, Frossard N. Cyclosporine does not affect in vitro bronchial smooth muscle contractions in treated Lewis rats. J Heart Lung Transplant 1994; 13: 520-524.

28 Bonnet S, Rochefort G, Sutendra G, et al. The nuclear factor of activated $\mathrm{T}$ cells in pulmonary arterial hypertension can be therapeutically targeted. Proc Natl Acad Sci USA 2007; 104: 11418-11423.

29 Shields GW, Sheller JR, Newman JH, et al. Airway responsiveness in isolated perfused rat lungs: effect of thoracic irradiation. Respir Physiol 1989; 78: 135-144.

30 Ding DJ, Martin JA, Macklem PT. Effect of lung volume on maximal methacholine-induced bronchoconstriction in normal humans. J Appl Physiol 1987; 62: 1324-1330.

31 Bates JH, Schuessler TF, Dolman C, Eidelman DH. Temporal dynamics of acute isovolume bronchoconstriction in the rat. J Appl Physiol 1997; 82: 55-62.

32 Noble P, McFawn PK, Mitchell HW. Responsiveness of the isolated airway during simulated deep inspirations: effect of airway smooth muscle stiffness and strain. J Appl Physiol 2007; 103: 787-795.

33 Salerno FG, Pellegrino R, Trocchio G, Spanevello A, Brusasco V, Crimi E. Attenuation of induced bronchoconstriction in healthy subjects: effects of breathing depth. J Appl Physiol 2005; 98: 817-821. 